\title{
Fitotoxicidade de água superficial da Região Metropolitana de São Paulo utilizando bioensaio com Sinapis alba
}

\author{
Marcio Yukihiro Kohatsua ${ }^{a^{*}}$, Tatiane Araújo de Jesus ${ }^{b}$, Lucia Helena Gomes Coelhob, Damáris \\ Cristina Peixotoc, Geovana Tognella Pocciac, Colin Hunterd \\ a Laboratório de Caracterização de Matrizes Ambientais, Universidade Federal do ABC, Santo André, São Paulo, 09210-580, Brasil. \\ *mykohatsu@aluno.ufabc.edu.br \\ b Programa de Pós-Graduação em Ciência e Tecnologia Ambiental, Universidade Federal do ABC, Santo André, São Paulo, 09210-580, \\ Brasil. \\ ${ }^{c}$ Laboratório de Caracterização de Matrizes Ambientais, Universidade Federal do ABC, Santo André, São Paulo, 09210-580, Brasil. \\ ${ }^{d}$ Glasgow Caledonian University, Glasgow, Scotland, United Kingdom.
}

Recebido: 21 fevereiro 2018 / Aceito: 21 maio 2018 / Publicado online: 28 maio 2018

\begin{abstract}
Resumo
Esta pesquisa teve por objetivo avaliar a fitotoxicidade de águas superficiais da Região Metropolitana de São Paulo utilizando bioensaios com Sinapis alba (sementes de mostarda), bem como a sua relação com a condutividade elétrica e sólidos dissolvidos totais. Foram realizadas 3 coletas no período de seca de 2017 (menor diluição de poluentes). As coletas foram realizadas em triplicata, em duas estações de amostragem (Referência e Córrego Ribeirão Pires). As variáveis respostas observadas foram: o crescimento radicular da $S$. alba, a porcentagem relativa de germinação, a porcentagem relativa de crescimento radicular, o Índice de Germinação (IG), além da aferição in locu da condutividade elétrica e dos sólidos dissolvidos totais, utilizando sonda multiparamétrica. As amostras da estação Referência foram classificadas como não fitotóxicas (IG = 93,55 $\pm 0,17 \%$ ), enquanto as amostras do Córrego Ribeirão Pires apresentaram fitotoxicidade moderada ( $I G=70,88 \pm 0,25 \%$ ). Desse modo, o despejo de águas residuárias no Córrego Ribeirão Pires oferece risco à manutenção da qualidade da água da Represa Billings, onde esse córrego deságua.
\end{abstract}

Palavras-chave: Ensaios Fitotoxicológicos, Índice de germinação, Poluição aquática.

\section{Phytotoxicity of surface water of the São Paulo Metropolitan Region using bioassay with Sinapis alba}

\begin{abstract}
This research aimed to evaluate the phytotoxicity of surface waters of the São Paulo metropolitan region using bioassays based on Sinapis alba L. (mustard). Three sampling campaigns were carried out during the dry season of 2017 (minimum dilution of pollutants) and samples were collected in triplicate at two locations (Reference and Ribeirão Pires stream). The assays were performed in triplicate to increase the degree of reliability of the information obtained. The observed responses were: root growth of $S$. alba, relative percentage of germination, relative percentage of root growth, Germination Index (GI). Electrical conductivity and total dissolved solids were also measured in situ using a multiparametric probe. The reference samples were classified as non-phytotoxic ( $\mathrm{IG}=93.55 \pm 0.17 \%$ ), while Ribeirão Pires stream samples showed moderate phytotoxicity $(\mathrm{IG}=$ $70.88 \pm 0.25 \%)$. Thus the discharge from the Ribeirão Pires stream into the billings Dam poses a risk to the water quality of the dam, especially where this stream drains.
\end{abstract}

Keywords: Germination Index, Phytotoxicological testing, Water pollution.

\section{Introdução}

O lançamento direto de esgotos não tratados e/ou ineficientemente tratados em corpos d'água torna bastante complexa a caracterização da qualidade da água, devido à variedade de composição de tais efluentes, os quais, na maioria dos casos, consistem de substâncias complexas e de difícil análise.
Assim, os ensaios ecotoxicológicos podem contribuir com a caracterização dessas matrizes complexas, visto que permitem a classificação das amostras quanto ao nível de toxicidade que apresentam aos organismos testes. Entretanto, estas normativas envolvem o emprego de organismos de difícil cultivo em laboratório e/ou muito onerosos.

A fitotoxicologia, ramo da ecotoxicologia, analisa a toxicidade de uma substância em relação a algumas espécies 
de plantas. É importante ressaltar que, durante os estágios iniciais de desenvolvimento, as sementes são mais sensíveis ao estresse ambiental, o que contribui para a sua utilização em testes de fitotoxicidade (Guerra, 2009). Além disso, ensaios com sementes (como a $S$. alba) são relevantes por fornecerem classificação quanto ao nível de toxicidade e serem de rápida execução e ter baixo custo experimental.

Guerra (2009) reitera que a análise fitotóxica é um dos métodos mais utilizados para avaliar a toxicidade das amostras de água e sedimento devido à sensibilidade que as sementes possuem. Além disso, Belo (2011) recomenda que estes testes devem ser utilizados de modo integrado com outros parâmetros químicos para melhor precisão dos resultados obtidos.

Assim, a avaliação da fitotoxicidade com sementes apresenta potencial como mais uma linha de evidência no contexto da caracterização de águas residuárias e tratadas antes de seu lançamento em corpos d'água, bem como no monitoramento da qualidade da água de mananciais de abastecimento público, o que vai de encontro com o princípio de múltiplas barreiras sanitárias. Reali et al. (2013) afirmam que os sistemas de abastecimento de água devem incorporar barreiras sanitárias sequenciais, de forma a reduzir o risco sanitário associado à água, até sua chegada ao consumidor final. Ou seja, a segurança do abastecimento público de água deve ser garantida através de várias etapas, sendo regulamentada pelo monitoramento da qualidade da água do manancial por diversos parâmetros físico-químicos e microbiológicos.

Desse modo, os ensaios ecotoxicológicos também podem contribuir com a avaliação da qualidade e a garantia da segurança do abastecimento de água. Nesse sentido, alguns ensaios ecotoxicológicos já regulamentados pela Associação Brasileira de Normas Técnicas, ABNT, estão sendo utilizados pela Companhia Ambiental do Estado de São Paulo, CETESB (CETESB, 2013), tais como: a NBR 15411 utilizando a Vibrio fischeri (ABNT, 2012) e a NBR 12713 utilizando a Daphnia similis (ABNT, 2016).

Assim, esta pesquisa teve por objetivo avaliar a fitotoxicidade de águas superficiais da Região Metropolitana de São Paulo utilizando bioensaios com Sinapis alba (sementes de mostarda), bem como a sua relação com a condutividade elétrica e sólidos dissolvidos totais.

\section{Material e Métodos}

\section{Caracterização da área de estudo}

A Represa Billings está situada integralmente nos municípios de Rio Grande da Serra e, parcialmente, nos municípios de Diadema, Ribeirão Pires, Santo André, São Bernardo do Campo e São Paulo, localizados na Região Metropolitana do Estado de São Paulo (Santo André, 2014). A Represa subdivide-se em oito braços principais, correspondentes aos cursos d'água que são seus formadores: Alvarenga, Bororé, Capivari, Cocaia, Pedra Branca, Rio Grande, Rio Pequeno e Taquacetuba (Santo André, 2014).

O Braço Rio Grande integra o Sistema Produtor de Água Rio Grande, o qual, atualmente, abastece mais de 1,5 milhão de habitantes nos municípios de Diadema, Santo André e São

\section{Bernardo do Campo (SABESP, 2017).}

O Braço Rio Grande possui área de cerca de 7,4 km². É um dos principais corpos hídricos formadores do reservatório Billings e, historicamente, é nele que ocorre a captação para abastecimento humano (De Oliveira, 2012). Devido às crises qualitativas ocorridas em 1981, o Braço Rio Grande foi totalmente isolado do restante da represa para preservar a qualidade das águas locais, visando manter os padrões de potabilidade (De Oliveira, 2012; Santo André, 2014). Todavia, ainda recebe grandes quantidades de esgoto não tratado ou tratado ineficientemente por condomínios residenciais e estabelecimentos comerciais localizados no entorno do reservatório (De Oliveira, 2012; Santo André, 2014).

Ao longo do Braço Rio Grande estão localizadas a Estação de Tratamento (ETA) Rio Grande, com vazão de captação de água para abastecimento de $5 \mathrm{~m}^{3} \mathrm{~s}^{-1}$ (SABESP, 2017) e a Estação de Tratamento de Esgotos Parque Andreense (ETEPA), ligada ao Serviço Municipal de Saneamento Ambiental de Santo André - SEMASA (De Oliveira, 2012; Santo André, 2014). Este manancial é aproveitado para usos múltiplos, tais como: recreação, pesca, abastecimento público, além de ser receptor de dejetos industriais e domésticos.

Segundo a Resolução CONAMA no 357/2005 (Brasil, 2005) o Braço Rio Grande é enquadrado na Classe II (São Paulo 1977), portanto, devem ser mantidos os requisitos de qualidade de água referentes a tal classe a fim de garantir seus usos preponderantes.

\section{Coleta das amostras}

As coletas de amostras de água foram realizadas em duas estações: (1) Córrego Ribeirão Pires e (2) Região mais preservada do Braço Rio Grande da Represa Billings, utilizada como Referência. Ambas as estações são localizadas na Região Metropolitana de São Paulo (RMSP; Figura 1).

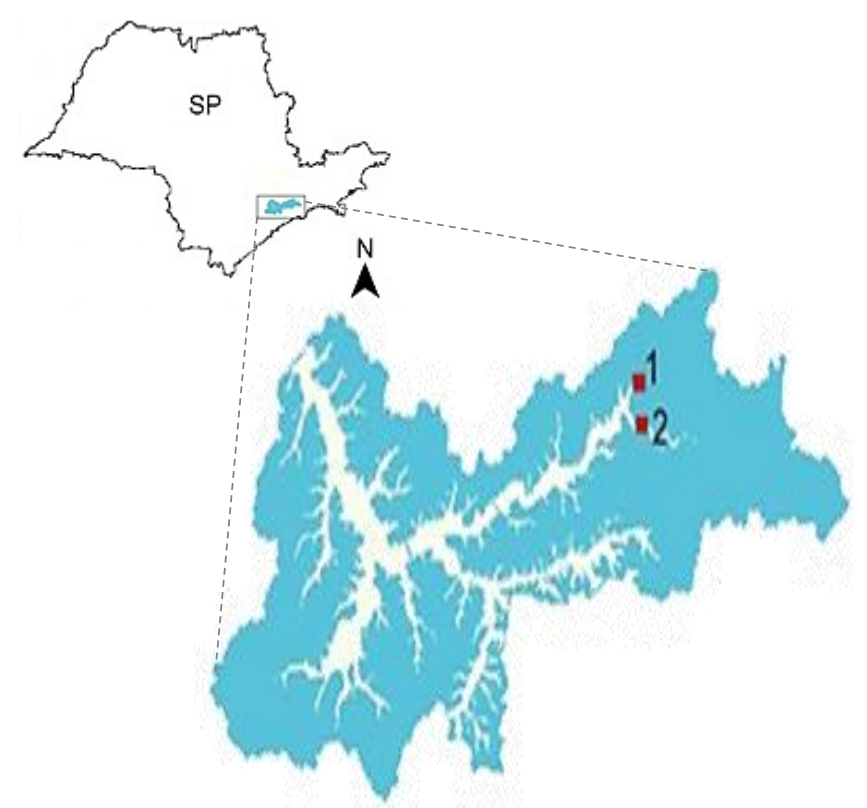

Figura 1. localização da Represa Billings no Estado de São Paulo (esquerda), com a localização (direita) das estações de amostragem no Braço Rio Grande da Represa Billings: (1) 
Córrego Ribeirão Pires; (2) Referência.

O Córrego Ribeirão Pires foi escolhido porque é bastante degradado pelo lançamento inadequado de esgotos brutos e deságua diretamente neste braço da Represa Billings. As coordenadas geográficas e características gerais de uso e ocupação da área de entorno das estações de amostragem estão descritas na Tabela 1.

Tabela 1. Coordenadas Geográficas e características gerais das estações de coleta.

\begin{tabular}{cl}
\hline Estação/Coordenada & \multicolumn{1}{c}{ Característica } \\
\hline Referência & Bairro Califórnia paulista. Área \\
$23^{\circ} 44^{\prime} 4,7^{\prime}, \mathrm{S}$ & $\begin{array}{l}\text { preservada, majoritariamente } \\
\text { nativa. }\end{array}$ \\
$46^{\circ} 25^{\prime} 38^{\prime}, \mathrm{W}$ & Bairros Jardim Santa Inês e Vila \\
& Suissa, Ribeirão Pires - SP. Área \\
Córrego Ribeirão & $\begin{array}{l}\text { Residencial no entorno com grande } \\
\text { Pires }\end{array}$ \\
$23^{\circ} 42^{\prime} 54,1^{\prime}, \mathrm{S}$ & quantidade de resíduos nas \\
$46^{\circ} 25^{\prime} 46,5^{\prime}, \mathrm{W}$ & margens. Odor desagradável. \\
& Presença de esgoto bruto. \\
\hline
\end{tabular}

As amostras de água foram coletadas em triplicatas $(\mathrm{n}=$ 3) na região subsuperficial da coluna d'água (cerca de $10 \mathrm{~cm}$ ) e armazenadas em frascos plásticos até chegarem ao Laboratório de Caracterização de Matrizes Ambientais da Universidade Federal do ABC (UFABC, Santo André, SP), onde foram congeladas $\left(-20^{\circ} \mathrm{C}\right)$ para preservação até o dia da análise. As campanhas de amostragem foram realizadas nos dias 19 de junho, 28 de julho e 23 de agosto de 2017, ou seja, todas no período de seca para a região, quando se espera menor diluição, ou seja, provável cenário mais crítico quanto à poluição do corpo d'água.

Ainda em campo, foram realizadas, em triplicata, as determinações da condutividade elétrica (CE) e dos sólidos dissolvidos totais (SDT) por meio de uma sonda multiparamétrica da marca Horiba (modelo U50) previamente calibrada. A CE representa a capacidade de condução de corrente elétrica que a água possui e que está correlacionada com os compostos iônicos dissolvidos (CETESB, 2014); e os sólidos dissolvidos totais (SDT) constituem uma medida do conteúdo de sais e de minerais da água (Reali et al., 2013).

\section{Bioensaios com semente de Sinapis alba}

Os ensaios fitotoxicológicos seguiram a metodologia de Belo (2011) e Vieira (2016). O teste de fitotoxicidade baseiase na inibição do crescimento radicular nos primeiros três dias do período de germinação das plantas.

O experimento foi desenvolvido em placas de Petri $(90$ $\mathrm{mm}$ ), com papel filtro no fundo, umedecendo-o com $3 \mathrm{~mL}$ da amostra a ser testada, a saber: água da Estação Referência; do Córrego Ribeirão Pires e água ISO (controle positivo). Todas as amostras foram preparadas em triplicatas, com 6 sementes de mostarda de maneira centralizada em cada placa de Petri. Em seguida, as placas foram deixadas na horizontal por cerca de 10 minutos para fixação, tampadas e vedadas com filme plástico para evitar perda de água por evaporação. As placas de Petri foram colocadas em uma incubadora na posição vertical, sem exposição à luz e à temperatura de $(21 \pm 2)^{\circ} \mathrm{C}$ durante o período total de três dias (72 horas).

As variáveis respostas analisadas foram o número de sementes germinadas e o crescimento radicular através da medição do comprimento das sementes, utilizando paquímetro digital (precisão de $0,001 \mathrm{~cm}$ ).

O cálculo da porcentagem relativa de germinação (\%RSG) em cada placa, foi utilizada a Equação 1, onde:

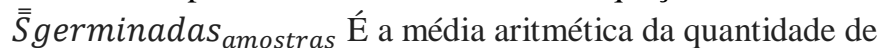
sementes germinadas nas amostras; $\overline{\bar{S}}$ germinadas controle É a média aritmética da quantidade de sementes germinadas no controle.

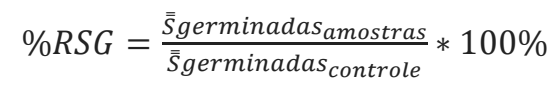

Para calcular a porcentagem relativa de crescimento radicular (\%RRG) em cada placa, foi determinada a razão entre a média aritmética do comprimento das raízes das amostras e a média aritmética do comprimento das raízes do controle.

\section{Índice de Germinação}

O Índice de Germinação (IG) foi calculado utilizando a Equação 2.

$$
I G=\frac{\% R S G * \% R R G}{100}
$$

O nível de fitotoxicidade das amostras da Represa Billings foi calculado de acordo com a classificação utilizada por Belo (2011), com o auxílio da Tabela 2.

Tabela 2. Classificação qualitativa de fitotoxicidade.

\begin{tabular}{cl}
\hline IG & Classificação do material em análise \\
\hline$>100$ & $\begin{array}{l}\text { O material potencializa a germinação e o } \\
\text { crescimento das raízes das plantas }\end{array}$ \\
$80-100$ & Não Fitotóxico, composto maturado \\
$60-80$ & Moderadamente Fitotóxico \\
$30-60$ & Fitotóxico \\
$<30$ & Muito Fitotóxico \\
\hline Fonte: Adaptado de Belo (2011).
\end{tabular}

Fonte: Adaptado de Belo (2011).

Os dados foram analisados estatisticamente por meio de análise de variância (ANOVA) e teste de Tukey, a 5\% de probabilidade. Além disso, a fim de avaliar a relação entre as variáveis, foi realizado teste de correlação de Pearson. Utilizou-se o programa computacional PAST (Hammer, 2001) para essa avaliação.

\section{Resultados e Discussão}

No Córrego de Ribeirão Pires os valores médios de CE e de SDT foram, respectivamente, de 266,33 $\pm 5,88 \mu \mathrm{S} \mathrm{cm}^{-1}$ e $173,44 \pm 3,89 \mathrm{mg} \mathrm{L}^{-1}$ (Tabela 3 ), ou seja, cerca de 8 vezes maior que na estação Referência. Na Resolução CONAMA 357/2005 (BRASIL, 2005) não existe valor estabelecido para a condutividade elétrica. Entretanto, Gasparotto (2011) afirma que o valor típico de CE em esgotos brutos pode variar de 100 a $1000 \mu \mathrm{S} \mathrm{cm}^{-1}$. Já para SDT, o valor limite para corpos d'água doces Classe II é de $500 \mathrm{mg} \mathrm{L}^{-1}$. Os valores de CE e SDT 
obtidos para o Córrego Ribeirão Pires são comparáveis aos obtidos por Rodrigues et al. (2018) para a foz do Córrego Água Limpa, São Paulo, cuja microbacia apresenta intensa atividade agrícola e urbana. Assim, os valores mais elevados de CE e SDT no córrego Ribeirão Pires, em relação à Referência, são, provavelmente, relacionados aos despejos de águas residuárias no corpo hídrico. De fato, durante as campanhas de amostragem, notou-se presença de resíduos sólidos na foz do Córrego Ribeirão Pires e as águas apresentavam forte odor (Figura 2).

Tabela 3. Valores médios, com desvios padrões, das variáveis analisadas.

\begin{tabular}{lccc}
\hline \multirow{2}{*}{ Variável } & & \multicolumn{2}{c}{ Estação } \\
\cline { 3 - 4 } & Coleta & $\begin{array}{c}\text { Córrego Ribeirão } \\
\text { Pires }\end{array}$ & Referência \\
\hline \multirow{2}{*}{ Condutividade } & 1 & $259,33 \pm 1,15$ & $36,00 \pm 0,00$ \\
elétrica & 2 & $323,00 \pm 13,11$ & $48,00 \pm 1,00$ \\
$\left(\mu \mathrm{S} \mathrm{cm}^{-1}\right)$ & 3 & $217,66 \pm 3,51$ & $20,33 \pm 3,51$ \\
& Média & $266,33 \pm 5,88$ & $34,77 \pm 1,51$ \\
\hline Sólidos & 1 & $168,33 \pm 1,15$ & $23,00 \pm 0,00$ \\
dissolvidos & 2 & $210,33 \pm 8,02$ & $31,00 \pm 0,00$ \\
totais & 3 & $141,66 \pm 2,51$ & $13,00 \pm 2,00$ \\
$\left(\right.$ mg L $\left.{ }^{-1}\right)$ & Média & $173,44 \pm 3,89$ & $22,33 \pm 0,66$ \\
\hline \multirow{2}{*}{ Comprimento } & 1 & $6,81 \pm 0,14$ & $8,22 \pm 0,21$ \\
radicular & 2 & $6,87 \pm 0,13$ & $9,03 \pm 0,16$ \\
$($ cm) & 3 & $7,18 \pm 0,09$ & $9,09 \pm 0,11$ \\
& Média & $6,95 \pm 0,12$ & $8,78 \pm 0,16$ \\
\hline \multirow{2}{*}{ Índice de } & 1 & $69,39 \pm 0,23$ & $93,17 \pm 0,24$ \\
Germinação & 2 & $70,07 \pm 0,50$ & $92,89 \pm 0,20$ \\
$(\%)$ & 3 & $73,18 \pm 0,04$ & $94,59 \pm 0,08$ \\
& Média & $70,88 \pm 0,25$ & $93,55 \pm 0,17$ \\
\hline
\end{tabular}

Data das coletas (2017): 1 (19/06); 2 (28/07); 3 (23/08).

Todas as sementes de $S$. alba germinaram nos ensaios de ambas as estações (\%RSG $=100 \%)$. Kapusta (1997) e Hillis et al. (2011) afirmam que o teste de germinação é relativamente insensível para algumas substâncias e níveis de

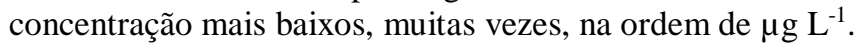
Os comprimentos radiculares médios, nos ensaios da estação Referência e Córrego Ribeirão Pires foram estatisticamente diferentes, apresentando valores iguais a 6,95 $\pm 0,12$ e 8,78 \pm $0,16 \mathrm{~cm}$, respectivamente.

O IG médio nos experimentos da estação Referência foi igual a 93,55 $\pm 0,17 \%$, o que classifica essas águas como não fitotóxicas, segundo Belo (2011). Esse resultado era esperado, pois a Estação Referência é um local com vegetação majoritariamente nativa e sem contribuições aparentes de lançamentos de águas residuárias.

Para os experimentos do Córrego Ribeirão Pires o IG médio foi igual a $70,88 \pm 0,25 \%$, sendo essas amostras classificadas como moderadamente fitotóxicas. Embora o IG das amostras de água do córrego tenha aumentado entre os dias de coleta (Tabela 3), as amostras ainda estão no intervalo de classificação moderada para a sua fitotoxicidade. Essa classificação, provavelmente, deve estar relacionada ao lançamento inadequado de esgotos domésticos não tratados e resíduos no córrego, acarretando nível de fitotoxicidade mais acentuado neste local, quando comparado com a estação de Referência.

No Córrego de Ribeirão Pires os valores de CE e SDT foram cerca de 8 vezes maiores que na Estação Referência. Os altos valores de CE (presença de compostos iônicos) e SDT (presença de carbonato, bicarbonato, cloreto, sulfato, fosfato, nitrato, cálcio, magnésio, sódio entre outros íons) se relacionam com a inibição do crescimento radicular das sementes.

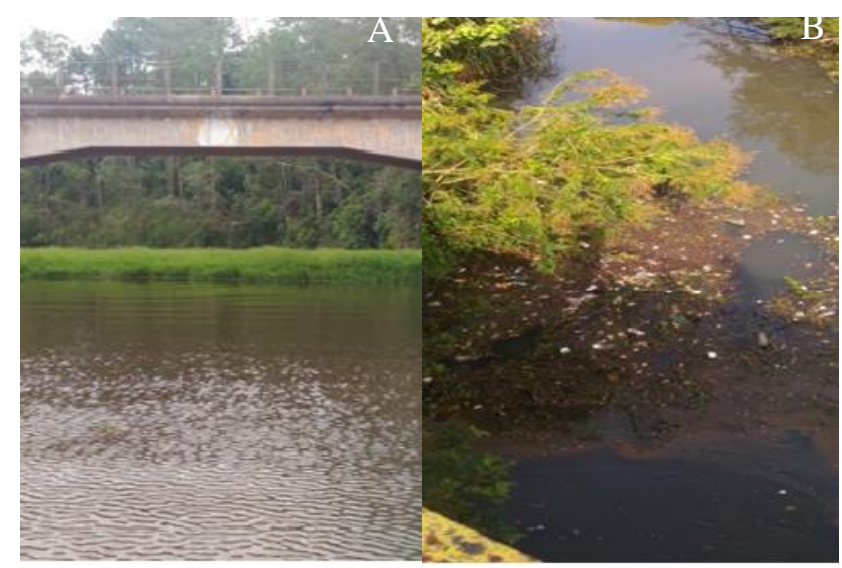

Figura 2. Estações de Amostragem: (A) Referência; (B) Córrego Ribeirão Pires.

Houve forte correlações entre os valores de IG, CE e SDT, sendo positiva entre CE e SDT $(R=0,98)$ e negativa entre IG e as demais variáveis (IG-CE e IG-SDT: $\mathrm{R}=-0,87$ ). Com a diminuição dos valores de CE e SDT, em ambas as estações, o IG calculado foi maior, sugerindo que, provavelmente, os altos valores de CE e SDT, são indicativos da presença de substâncias em concentrações que inibam o crescimento das sementes, como por exemplo, a presença de esgoto bruto. Gasparotto (2011) afirma que o valor típico de CE para esgoto bruto varia de 100 a $1000 \mu \mathrm{S}$ cm-1 e o Córrego Ribeirão Pires possui valor médio de CE acima de $266 \mu \mathrm{S} \mathrm{cm}-1$.

Burton et al. (2001) avaliaram a toxicidade de amostras de sedimento do lago Orta, na Itália. Neste estudo, caracterizouse a concentração de chumbo, zinco, cobre, níquel e cromo e estes dados foram relacionados com a inibição causada no crescimento das sementes de pepino. Dentre as três estações analisadas, a estação Ômega apresentou as mais altas concentrações de metais e a Estação Buccione apresentou a menor concentração dos metais analisados. O IG dos bioensaios realizados com os extratos das amostras de sedimento foram de 68\% para a estação Ômega e $100 \%$ para a estação Buccione. Os valores obtidos por Burton et. al (2001) são similares aos do presente estudo. A estação Referência apresentou IG de 93,55\%, similar a estação Ômega. O córrego Ribeirão Pires apresentou IG de 70,88\%, similar a estação Buccione.

Os resultados de IG obtidos para o Córrego Ribeirão Pires ficaram entre $65 \%$ e $70 \%$, os quais são semelhantes aos obtidos por Dash (2012), onde foi avaliada a fitotoxicidade de amostras de esgoto doméstico bruto através de bioensaios com sementes de arroz. Isso pode indicar que ocorre lançamento de esgoto doméstico bruto no Córrego.

\section{Conclusões}


Os bioensaios com $S$. alba classificaram a estação Referência como não fitotóxica pelo IG. Esse resultado deve estar relacionado com a preservação e proteção do local. Entretanto, o Córrego Ribeirão Pires apresentou fitotoxicidade moderada para a $S$. alba, provavelmente, pelos lançamentos de efluentes no córrego e a presença de resíduos sólidos em seu entorno. Os valores de IG estão fortemente correlacionados com os valores de CE e SDT.

Desse modo, recomenda-se que o Município de Ribeirão Pires melhore o seu sistema de coleta e tratamento de suas águas residuárias, antes do lançamento no Córrego Ribeirão Pires, que deságua no Braço Rio Grande da Represa Billings.

\section{Referências}

ABNT, 2012. NBR 15411-3: Ecotoxicologia aquática - Determinação do efeito inibitório de amostras aquosas sobre a emissão da bioluminescência de Vibrio fischeri (ensaio de bactéria luminescente) Parte 3: Método utilizando bactérias liofilizadas.

ABNT, 2016. NBR 12713: Toxicidade aguda - Método de ensaio com Daphnia spp (Crustacea, Cladocera).

Belo, S. R. S. 2011. Avaliação de fitotoxicidade através de Lepidium sativum no âmbito de processos de compostagem. Dissertação de Mestrado, Universidade de Coimbra, Coimbra. 79p.

Bernal, M., Alburquerque, J., Moral, R., 2009. Composting of animal manures and chemical criteria for compost maturity assessment. A review. Bioresource Technology, 100(22): 5444-5453.

Burton JR; Allen G.; Baudo, R.B., Monica, B. 2001. Assessing sediment contamination using six toxicity assays. Journal of Limnology, 60(2): 263-267.

Brasil, 2005. Resolução CONAMA n. 357 de 18 de março de 2005. Brasília, DF: Ministério do Meio Ambiente. Acesso em: 27/05/2018.

CETESB, 2013. Controle Ecotoxicológico de Efluentes Líquidos no Estado de São Paulo. Acesso em 02/05/2018.

CETESB. 2014. Apêndice D - Índice de qualidade das águas. Acesso em $21 / 03 / 2018$

Dash, A. K. 2012. Impact of domestic waste water on seed germination and physiological parameters of rice and wheat. International Journal of Research and Reviews in Applied Sciences, 12(2): 280-286.

DataGeo, 2017. Infraestrutura de Dados Espaciais Ambientais do Estado de São Paulo. Acesso em 07/03/2018.

De Oliveira, T.A. 2012. Metais presentes na água e em tecidos de peixes da Represa Billings: uma avaliação temporal. Dissertação de Mestrado, Instituto de Pesquisas Energéticas e Nucleares, São Paulo. 215p.

Gasparotto, F. A.; 2011. Avaliação Ecotoxicológica e Microbiológica da água de nascentes urbanas no município de Piracicaba-SP, Dissertação de Mestrado, Universidade de São Paulo. Piracicaba, 90p.

Guerra, R. C. 2009. Estudo do lodo gerado em reator biológico, pelo tratamento da água de produção do petróleo, no Terminal marítimo Almirante Barroso, município de São Sebastião, SP, visando sua disposição final. Dissertação de Doutorado, Universidade Estadual Paulista, Rio Claro. 126p.

Hammer, Ø.; Harper, D.A.T.; Ryan, P.D. 2001. PAST: Paleontological statistics software package for education and data analysis. Palaeontologia Electronica, 4(1): 1-9.

Hillis, D.G.; Fletcher, J.; Solomon, K.R.; Sibley, P. 2011. Effects of ten antibiotics on seed germination and root elongation in three plant species. Archives of Environmental Contamination and Toxicology. 60(2): 220-232

Reali, M.A.P.; Paz, L.P.S.; Daniel, L.A. 2013. Tratamento de água para consumo humano. In. Calijuir, M.C.; Cunha, D.G.F. (1 ed). Engenharia Ambiental: Conceitos, Tecnologia e Gestão. Elsevier, Rio de Janeiro. p.405-453.

Santo André. 2014. A Represa Billings e o município de Santo André. Acesso em: 15/02/2017.

SABESP, 2017. Boletim dos Mananciais. Acesso em 14/07/2017.

Vieira, L.A. 2016. Compostagem de biossólido de estação de tratamento de efluentes de frigorífico com serragem e cama de aves. Dissertação de Mestrado, Universidade Federal de Pelotas, Rio Grande do Sul, 66p.

Waissmann, W. 2002. Health surveillance and endocrine disruptors. Cadernos de Saúde Pública, 18(2): 511-517.

Trautmann, N.; Krasny, M. 1997. Composting in the Classroom, Scientific Inquiry for High School Students. Ed. Cornell University, Ithaca, New York, p 79-83. 